einstein

Official Publication of the Instituto Israelita

de Ensino e Pesquisa Albert Einstein

ISSN: 1679-4508 | e-ISSN: 2317-6385

\title{
Visual data: a new tool to improve the presentation of clinical trial results
}

\author{
Dados visuais: uma nova ferramenta para melhorar a \\ interpretação dos resultados de ensaios clínicos \\ Raphael Mendes Ritti-Dias'1, Marilia de Almeida Correia', Breno Quintella Farah² \\ Universidade Nove de Julho, São Paulo, SP, Brazil. \\ 2 Universidade Federal Rural de Pernambuco, Recife, PE, Brazil.
}

DOI: 10.31744/einstein_journal/2020AE4729

\section{ABSTRACT}

Randomized controlled trials are known to be the best tool to determine the effects of an intervention; however, most healthcare professionals are not able to adequately understand the results. In this report, concepts, applications, examples, and advantages of using visual data as a complementary tool in the results section of original articles are presented. Visual simplification of data presentation will improve general understanding of clinical research.

Keywords: Randomized controlled trials as topic; Biostatistics; Data display; Non-randomized controlled trials as topic

\section{RESUMO}

Ensaios clínicos randomizados são conhecidos por serem a melhor ferramenta para determinar os efeitos de uma intervenção. No entanto, a maioria dos profissionais de saúde não é capaz de compreender os resultados de forma adequada. Neste artigo, são apresentados conceitos, aplicações, exemplos e vantagens do uso de dados visuais como uma ferramenta complementar na seção dos resultados de artigos originais. A simplificação da visualização da apresentação dos dados deve melhorar o entendimento geral de pesquisas clínicas.

How to cite this article: Ritti-Dias RM, Correia MA, Farah BO. Visual data: a new tool to improve the presentation of clinical trial results. einstein (São Paulo). 2020;18:eAE4729. http://dx.doi.org/10.31744/ einstein journal/2020AE4729

Corresponding author:

Raphael Mendes Ritti-Dias

Rua Vergueiro, 235/249 - Liberdade

Zip code: 01504-000 - São Paulo, SP, Brazil

Phone: (55 19) 99940-6878

E-mail: raphaelritti@gmail.com

\section{Received on:}

Aug 6, 2018

Accepted on:

June 12, 2019

Conflict of interest:

none.

Copyright 2019

(c) BY

This content is licensed

under a Creative Commons

Attribution 4.0 International License.
Descritores: Ensaios clínicos controlados aleatórios como assunto; Bioestatística; Apresentação de dados; Ensaios clínicos controlados não aleatórios como assunto

\section{| INTRODUCTION}

Randomized controlled trials (RCT) have been considered the most powerful experimental design tool to determine the effects of therapeutic interventions on patient outcomes. When performed well, RCT are considered the gold standard design to support decisions in clinical practice.

In order to appropriately interpret RCT results, the readers of a published trial need complete, clear, and transparent information on the trial methods and findings. ${ }^{(1)}$ Although important initiatives, such as Consolidated Standards of Reporting Trials (CONSORT), have brought significant improvement to $\mathrm{RCT}$ reporting, the adequate interpretation of trial results remains a challenge for researchers and practitioners.

An adequate understanding of statistical methods has been considered a major problem in translating RCT results to the scientific community. Although efforts have been made to improve the presentation of RCT results, the literature indicates that the majority of health practitioners are not able to 
adequately understand the results of clinical research. For example, in a multicenter study, Johnston et al.(2) observed that less than $30 \%$ of physicians had a correct understanding of frequent statistical methods employed in RCT, such as mean difference and minimal important difference. These results become more alarming when considering the variety and complexity of statistical procedures that have been used in RCT.(3)

A previous study identified that most practitioners perceived dichotomic variables as more valuable than continuous data for clinical decision making. (2) The simplification of presentation can be a way to improve the understanding of RCT results, helping to fill the gap between research and practice.

\section{VISUAL DATA: DEFINITION AND EXAMPLES}

Visual data has been widely used in business to facilitate the identification of problems in process chains. The idea is to provide visual schemes according to specified criteria, thus making the identification of successful and unsuccessful cases clearer. An example of single visual data is presented in figure 1 .
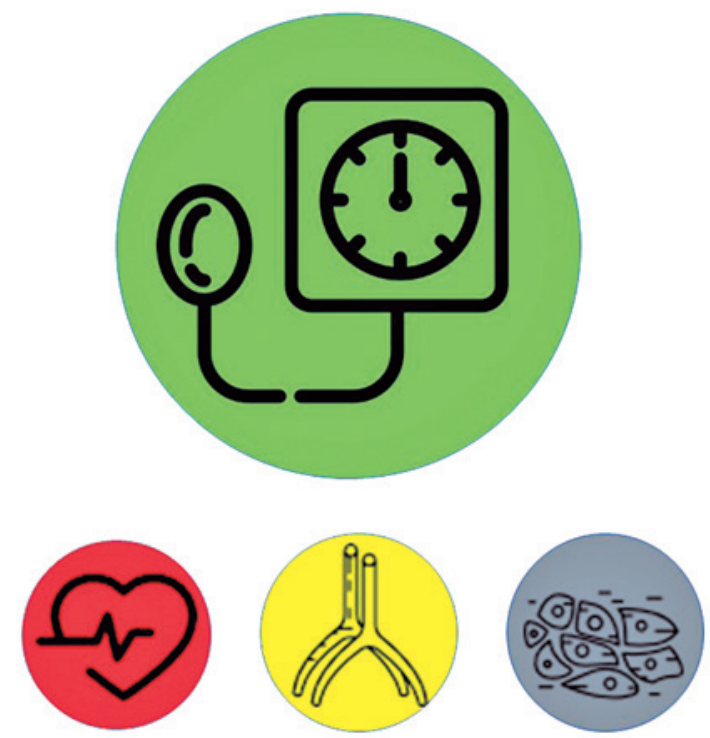

Figure 1. Identification of improvement (green), worsening (red), no change (yellow) or missing data (gray) of an intervention with primary (large symbol) and secondary (smaller symbols) variables

In the figure, the large circle represents the main outcome (blood pressure), while the other three small circles represent the secondary outcomes (heart rate, arterial stiffness, and endothelial function). Inside each circle, a visual image with a symbol of each outcome was included to facilitate figure interpretation. The results of the intervention in each variable are indicated by the colors inside each circle (improvement, green; maintenance, yellow; worsening, red; missing data, gray). Thus, in the exemplified case, the subject improved blood pressure, maintained arterial stiffness and worsened heart rate. The endothelial function data was not collected.

Figure 2 presents the data of an entire study including 80 subjects, 40 in Experimental Group and 40 in Control Group. Despite the inclusion of several subjects in the same chart, the interpretation of the results is clear. In the figure, it is possible to observe that most subjects in the Experimental Group improved the primary outcome, while only a few subjects in the Control Group improved in this variable. In addition, there was heterogeneity in response for secondary outcomes among subjects of the Experimental Group. For comparison, the same data of figure 2 are presented in table 1 , using the presentation pattern commonly used in RCT.

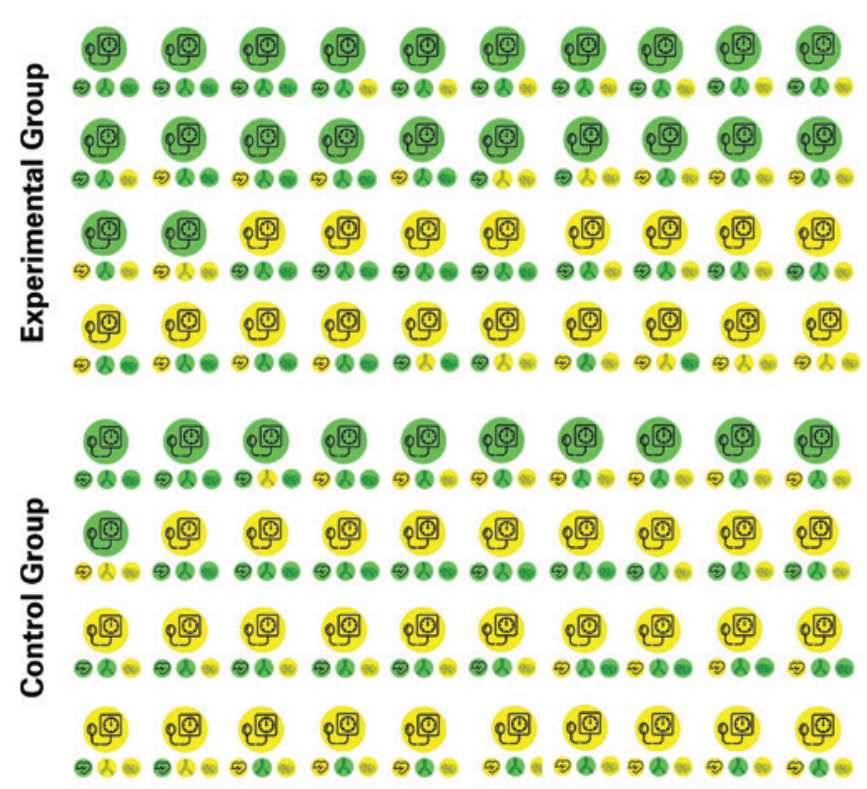

Figure 2. Data from a complete study including 80 subjects, 40 in the Experimental Group and 40 in the Control Group

Table 1. Data from the figure 2 presented as mean (standard deviation)

\begin{tabular}{lccccccccc}
\hline \multirow{2}{*}{ Variables } & \multicolumn{2}{c}{$\begin{array}{c}\text { Control } \\
\text { Group }\end{array}$} & & \multicolumn{2}{c}{$\begin{array}{c}\text { Experimental } \\
\text { Group }\end{array}$} & \multicolumn{2}{c}{$\begin{array}{c}\text { Time } \\
\text { effect }\end{array}$} & $\begin{array}{c}\text { Group } \\
\text { effect }\end{array}$ & $\begin{array}{c}\text { Interaction } \\
\text { effect }\end{array}$ \\
\cline { 2 - 3 } & Pre & Post & Pre & Post & & & \\
\hline $\begin{array}{l}\text { Blood pressure, } \\
\text { mmHg }\end{array}$ & $139(3)$ & $137(2)$ & $139(2)$ & $134(2)$ & $<0.001$ & $<0.001$ & $<0.001$ \\
$\begin{array}{l}\text { Heart rate } \\
\text { variability, ms }\end{array}$ & $24.0(3.5)$ & $24.9(4.2)$ & $23.4(4.0)$ & $24.7(3.4)$ & 0.069 & 0.495 & 0.648 \\
$\begin{array}{l}\text { Arterial } \\
\text { stiffness, } \mathrm{m} / \mathrm{s}\end{array}$ & $9.0(0.6)$ & $7.9(0.7)$ & $8.9(0.6)$ & $7.8(0.6)$ & $<0.001$ & 0.315 & 0.733 \\
$\begin{array}{l}\text { Endothelial } \\
\text { function, \% }\end{array}$ & $12.2(1.5)$ & $11.9(1.5)$ & $12.1(1.4)$ & $12.0(1.4)$ & 0.461 & 0.747 & 0.573 \\
\hline
\end{tabular}




\section{ADVANTAGES OF VISUAL DATA}

The presentation of individual data has increased in recent years in order to improve the reporting of RCT. In most cases, data is presented in line or bar charts (Figure 3), being each line or bar a subject. In most cases, only the primary outcome individual data are presented. When secondary outcomes are presented, they are included in different figures. A clear advantage of the proposed visual data compared to these graphs is the integrative view of intervention effects on primary and secondary outcomes for each subject. This allows for a more comprehensive interpretation, helping physicians better understand the effects of interventions on primary and secondary outcomes simultaneously.

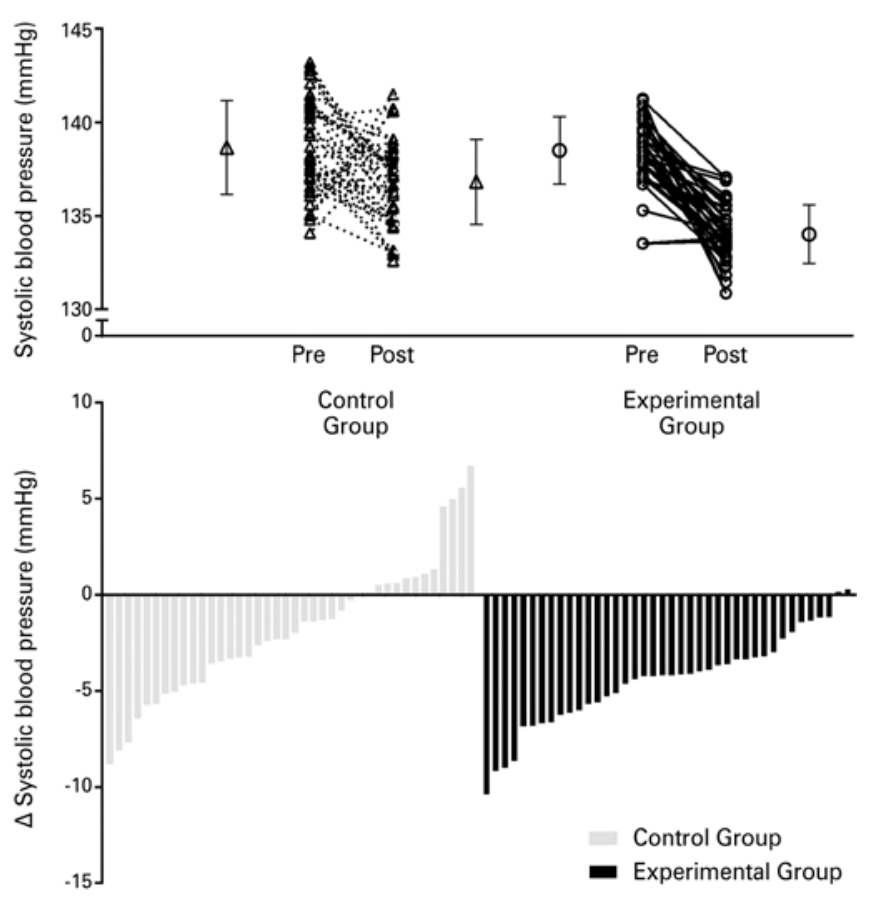

Figure 3. Individual data presented as lines or bars

The use of visual data implies that continuous variables should be transformed from numerical to categorical variables (improved, maintained or worsened). From a clinical point of view, this clarifies the clinical relevance of results. The use of categorical variables is also better for physicians. A previous study with 531 physicians from 8 countries reported that they best understood the dichotomous presentations of continuous outcomes and perceived them to be the most useful. (2) Hence, the utilization and extraction of data for healthcare professionals may be enhanced with visual data. A typical case in which this is helpful is presented in table 2 and figure 4 . As table 2 , statistically significant changes were observed in primary outcomes. However, visual data analysis suggested that no clinically meaningful alteration was verified.

Table 2. Data from the figure 4 presented as mean (standard deviation)

\begin{tabular}{lcccccccc}
\hline \multirow{2}{*}{ Variables } & \multicolumn{2}{c}{$\begin{array}{c}\text { Control } \\
\text { Group }\end{array}$} & & \multicolumn{2}{c}{$\begin{array}{c}\text { Experimental } \\
\text { Group }\end{array}$} & $\begin{array}{c}\text { Time } \\
\text { effect }\end{array}$ & $\begin{array}{l}\text { Group } \\
\text { effect }\end{array}$ & $\begin{array}{c}\text { Interaction } \\
\text { effect }\end{array}$ \\
\cline { 2 - 3 } & Pre & Post & & Pre & Post & & & \\
\hline Cerebral blood & 52.0 & 54.3 & & 52.1 & 52.2 & $<0.001$ & $<0.001$ & $<0.001$ \\
flow, $\mathrm{mL} / \mathrm{min}$ & $(0.2)$ & $(0.2)$ & & $(0.2)$ & $(0.3)$ & & & \\
Cognitive, score & 18.8 & 20.3 & & 19.1 & 20.2 & $<0.001$ & 0.488 & 0.213 \\
& $(0.6)$ & $(0.7)$ & & $(0.6)$ & $(0.8)$ & & & \\
\hline
\end{tabular}

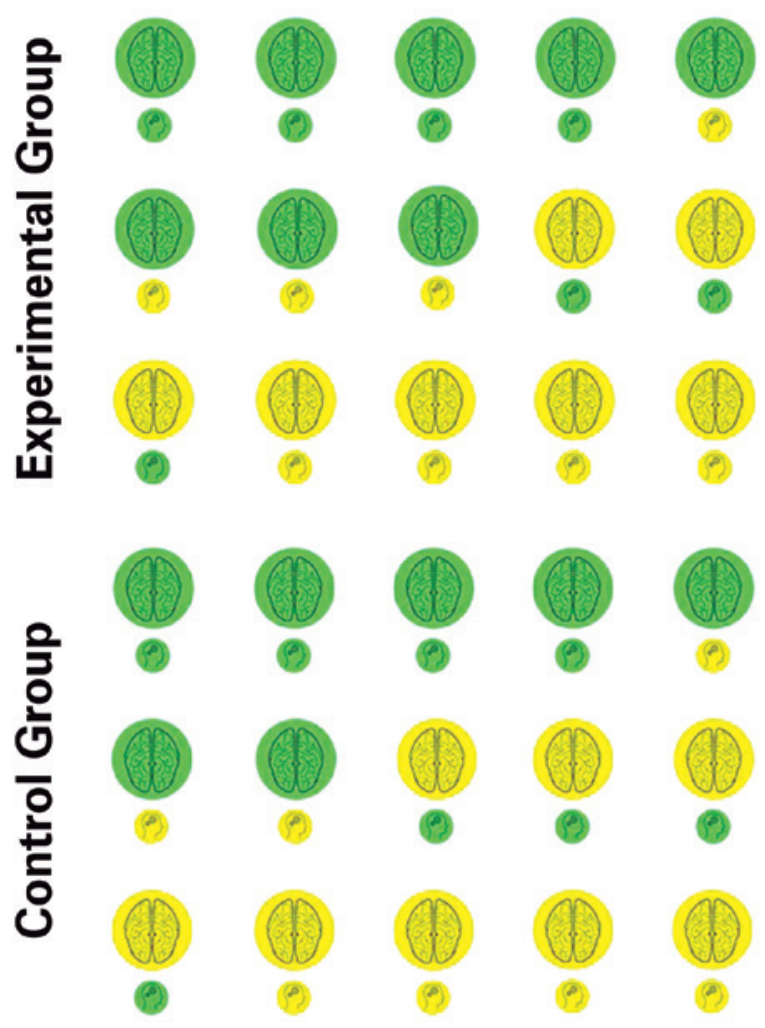

Figure 4. Representation of responses of an intervention in the Experimental Group and Control Group. Green indicates improvement, and yellow, maintenance

In addition, although the interventions aimed to improve the main outcome, it is possible that it may cause unwanted effects (adverse reactions) in some individuals. Still, the mean comparison, represented in numbers, does not allow identification of unwanted effects after intervention. For example, figure 5 (panel A) shows that, after an intervention, there was a statistically significant improvement in renal function - pre-values: 97.1 (2.1) versus post-values: 98.9 (3.7), with $\mathrm{p}=0.040$. 


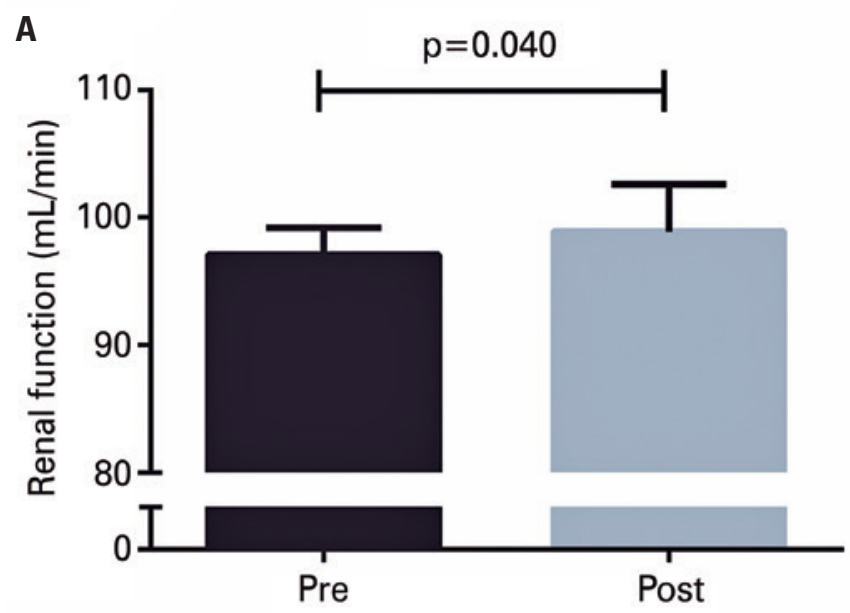

B

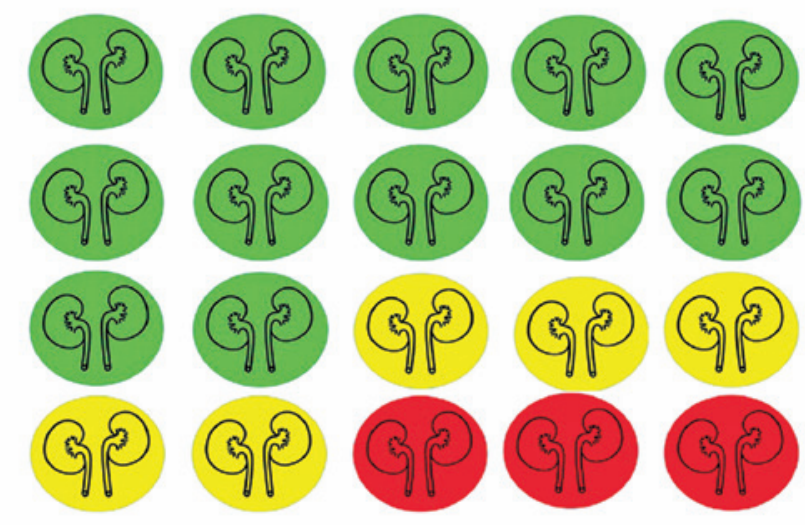

Figure 5. Pre- and post-intervention values for renal function (panel A) and visual data of individual responses. Green indicates improvement, yellow, maintenance, and red, worsening (panel B)

However, 25\% $(n=5)$ of the subjects did not show any improvement, and $15 \%(\mathrm{n}=3)$ presented adverse reactions, as shown in figure 5 (panel B).

The use of visual data may favor the dissemination of RCT results through non-scientific communication, such as television, blog and social networks media commonly used to inform the non-academic public interested in scientific research. ${ }^{(4)}$ This is an important topic given the growing interest of scientific journals in disseminating their articles to main public through social media (e.g. Facebook, Twitter and Instagram) ${ }^{(5)}$

In this sense, the current proposal is a first suggestion to use visual data as a tool to improve the interpretation of clinical trial results. Researchers and physicians are invited to employ this tool in different areas, to identify its feasibility in different contexts, allowing to refine and improve the utilization of visual data.

\section{DEFINING CUT-OFF POINTS}

Most physicians prefer dichotomous results to understand RCT results. ${ }^{(2)}$ It is known that for some outcomes, this type of result may leave doubts about the interpretation of findings. ${ }^{(3)}$ Cut-off point is defined as a main point in visual data. Several methods have been proposed to define the individual clinically relevant effect of interventions, and depending on the method employed, interpretation of visual data varies drastically.

The following main methods have been used to classify the effects of interventions:

- Delta zero: for some outcomes that usually change with treatment, if the delta (pre- and post-values) differs from zero, it indicates a response. ${ }^{(6)}$ This method can easily be argued, because it does not consider variations, such as reliability, random variability, and individual variations.

- Changes based on the risk: for some health variables, longitudinal studies have established cut-off points associated with health events. In this sense, some studies have used these clinically relevant values to classify the outcomes in RCT. For example, it is possible to classify subjects as responder if the blood pressure reduces to $3 \mathrm{mmHg}$, which is the value associated with fatal or non-fatal cardiovascular events. This criterion could be used for other variables as arterial stiffness $(1 \mathrm{~m} / \mathrm{s}),{ }^{(7)}$ resting heart rate $(75 \mathrm{bpm}),{ }^{(8)}$ flow-mediated dilation $(1 \%),{ }^{(9)}$ and biomarkers, ${ }^{(10)}$ among others.

- Tertiles and quartiles: outcomes have no established cut-off points, and some studies have used arbitrary values based on the median, tertiles, quartiles or percentiles, which can be contested. ${ }^{(11,12)}$

- Minimal detectable difference: it defines the difference between the means of a treatment and the control that must exist in order to conclude that there is a significant effect, beyond any measurement error with a given level of confidence, usually at $95 \%$ confidence level. For this, one must know the error of the measurement of the variable under analysis. ${ }^{(13)}$

\section{AUTHORS' INFORMATION}

Ritti-Dias RM: http://orcid.org/0000-0001-7883-6746

Correia MA: http://orcid.org/0000-0002-8983-3433

Farah BQ: http://orcid.org/0000-0003-2286-5892

\section{REFERENCES}

1. Schulz KF, Altman DG, Moher D, Group C. CONSORT 2010 Statement: updated guidelines for reporting parallel group randomised trials. Trials. 2010;11:32. 
2. Johnston B, Alonso-Coello P, Friedrich J, Mustafa R, Tikkinen K, Neumann I, et al. Do clinicians understand the size of treatment effects? A randomized survey across 8 countries. CMAJ. 2016;188(1):25-32.

3. Naggara 0, Raymond J, Guilbert F, Roy D, Weill A, Altman DG. Analysis by categorizing or dichotomizing continuous variables is inadvisable: an example from the natural history of unruptured aneurysms. Am J Neuroradiol. 2011;32(3):437-40.

4. Ramalho M, Arboleda T, Hermelin D, Reznik G, Massarani L. A cobertura de ciência em telejornais do Brasil e da Colômbia: um estudo comparativo das construções midiáticas. Hist Cienc Saude Manguinhos. 2017:24(1):223-42.

5. Souza UJ, Camilo G, Carmo RC, Silva EV. 0 uso das redes sociais pelos periódicos brasileiros de biblioteconomia e ciência da informação. Rev ACB. 2015;20(3):584-91.

6. Tibana RA, de Sousa NM, da Cunha Nascimento D, Pereira GB, Thomas SG, Balsamo S, et al. Correlation between acute and chronic 24-hour blood pressure response to resistance training in adult women. Int J Sports Med. 2015;36(1):82-9.

7. Vlachopoulos C, Aznaouridis K, Stefanadis C. Prediction of cardiovascular events and all-cause mortality with arterial stiffness: a systematic review and meta-analysis. J Am Coll Cardiol. 2010;55(13):1318-27. Review.
8. Fox K, Bousser MG, Amarenco P, Chamorro A, Fisher M, Ford I, et al. Heart rate is a prognostic risk factor for myocardial infarction: a post hoc analysis in the PERFORM (Prevention of cerebrovascular and cardiovascular Events of ischemic origin with terutroban in patients with a history of ischemic stroke or transient ischemic attack) study population. Int J Cardiol. 2013;168(4):3500-5.

9. Shechter M, Shechter A, Koren-Morag N, Feinberg MS, Hiersch L. Usefulness of brachial artery flow-mediated dilation to predict long-term cardiovascular events in subjects without heart disease. Am J Cardiol. 2014;113(1):162-7.

10. Guaricci Al, Pontone G, Fusini L, De Luca M, Cafarelli FP, Guglielmo M, et al. Additional value of inflammatory biomarkers and carotid artery disease in prediction of significant coronary artery disease as assessed by coronary computed tomography angiography. Eur Heart J Cardiovasc Imaging. 2017; 18(9):1049-56

11. Farah BQ, Ritti-Dias RM, Cucato GG, Montgomery PS, Gardner AW. Factors Associated with Sedentary Behavior in Patients with Intermittent Claudication. Eur J Vasc Endovasc Surg. 2016;52(6):809-14.

12. Machado M, Willardson J. Short recovery augments magnitude of muscle damage in high responders. Med Sci Sports Exerc. 2010;42(7):1370-4.

13. Negrete R, Hanney W, Kolber M, Davies G, Ansley M, McBride A, et al Reliability, minimal detectable change, and normative values for tests of upper extremity function and power. J Strength Cond Res. 2010;24(12): 3318-25 